Original article

\title{
Reproductive behavior in carrier couples for transfusion-dependent thalassemia major: evaluation of knowledge, attitude and practice
}

\author{
Mandana Zafari', Mehrnoush Kosaryan,", Mohammad Reza Mirzayi ${ }^{3}$ \\ (Received: 4 Dec 2015; Accepted: 1 Feb 2016)
}

\begin{abstract}
Background and Purpose: Despite extensive research on family planning and education, reproductive behavior of high-risk couples for thalassemia remains a major concern among medical professionals. This study aimed to evaluate the knowledge and attitude of carrier couples for transfusion-dependent thalassemia major (TDTM).

Methods: This case-control study was conducted 327 carrier couples for thalassemia minor. Contact information of the couples was obtained from three healthcare centers randomly selected from the eastern, central and western parts of Mazandaran province, Iran. To match the socioeconomic status, two control families (right and left neighbors) were interviewed per each carrier couple. Epidemiological characteristics and knowledge of the carrier couples were assessed via 10 and 20 questions, respectively, and scores above 15 were interpreted as adequate knowledge. Moreover, attitude of the subjects was evaluated via 16 items scored based on a four-point Likert scale. Data analysis was performed in SPSS V.16 using Mann-Whitney U test and T-test for the comparison of study groups, and $\mathrm{P}$ value of less than 0.05 was considered significant.

Results: In total, 327 high-risk couples for minor thalassemia and 660 control families were enrolled in this study. Among the subjects, $32.6 \%$ and $22.3 \%$ had adequate knowledge about thalassemia. In addition, attitude of the carrier couples was positive in $58 \%$ and $41 \%$ of the cases. Also, $30.5 \%$ and $31.2 \%$ of case and control subjects had favorable socioeconomic status, respectively.

Conclusion: According to the results of this study, knowledge of carrier couples was adequate with regard to TDTM, and they had a positive attitude toward receiving prenatal diagnosis for this syndrome. However, reproductive practice of high-risk couples was relatively poor. Therefore, it is recommended that reproductive behavior of high-risk couples for TDTM be monitored regularly in order to improve their practice.
\end{abstract}

Keywords: Attitude, Beta thalassemia minor, Couple, Genetic counseling, Iran, Knowledge, Practice, Prenatal diagnosis, Prevention, Transfusion-dependent thalassemia major

\section{Introduction}

National medical programs for the prevention of transfusion-dependent thalassemia major (TDTM) have been implemented for the past two decades $(1,2)$, and Mazandaran province in Iran has been a pioneer in this regard $(3,4)$. Premarital screening and genetic counseling for carrier couples are considered as the most effective strategies to prevent TDTM as they have been practiced in different countries since 1991 (1).
Screening for TDTM has been included in national healthcare programs since autumn 1997. In these programs, carrier couples receive counseling about TDTM and the risk of having thalassemic children, which leads to the informed decision of these couples regarding their reproductive behavior.

According to statistics, $11 \%$ of the population of Mazandaran province are carriers of $\beta$-thalassemia minor, $2 \%$ of couples are both carriers, and about

\footnotetext{
${ }^{1}$ Thalassemia Research Center, Mazandaran University of Medical Sciences, Department of Midwifery, Islamic Azad University, Sari Branch, Iran

${ }^{2,{ }^{*}}$ Corresponding author: Thalassemia Research Center, Mazandaran University of Medical Sciences, Sari, Iran. Email: mekowsarian@ gmail.com

${ }^{3}$ Vice President of Mazandaran University of Medical Sciences, Sari, Iran
} 
$50 \%$ of these couples decide to get married. Therefore, there are many high-risk families in this region $(3,4)$.

High-risk couples for TDTM who decide to get married are required to participate in special educational sessions in order to gain more knowledge about their condition, possible risk of having thalassemic children, family management and planning, prenatal diagnosis (PND), and legal grounds regarding the termination of high-risk pregnancies. Furthermore, carrier couples must comply with standard guidelines of family planning and contraception methods (1-4). Medical records of TDTM carrier couples are available in healthcare centers, and these individuals are visited regularly by health workers. In Iran, PND and abortion of fetuses suspected of thalassemia are considered legal for high-risk couples, and the costs are normally covered by insurance $(2,5-7)$.

To date, several studies have evaluated the reproductive behavior of high-risk couples for $\operatorname{TDTM}(2,3)$. Knowledge and attitude of carrier couples with regard to PND is of paramount importance. This study aimed to evaluate the knowledge and attitude of carrier couples for TDTM.

\section{Materials and Methods}

This case-control study was conducted in three healthcare centers randomly selected from the eastern, central, and western parts of Mazandaran province, Iran in 2012. Contact information of the carrier couples who had been married for at least one year was obtained from the medical archives of the selected healthcare centers. Sample size of the study was calculated at 400 subjects in each group $(\alpha=0.05,95 \%$ confidence interval [CI], $80 \%$ test power). In total, 327 carrier couples from the eastern, central, and western parts of Mazandaran province were enrolled in this study. Final sample size of the case and control groups was estimated at 327 and 660 subjects, respectively.

In this study, we considered two control families for each carrier couple. Families with children or close relatives diagnosed with thalassemia major and autosomal diseases were excluded from the study. Study groups were compared in terms of confounding variables, including age, socioeconomic status, duration of marriage, number of pregnancies, number of pregnancies per family, history of PND and medical abortion, use of reliable contraception methods, pregnancy without PND, and intentions for future pregnancy.

Data were collected using a questionnaire consisting of four main sections; the first section focused on epidemiological characteristics, and the other sections measured the knowledge, attitude, and reproductive practice of TDTM carrier couples. The questionnaire was designed in accordance with the results of previous studies in this regard (3). Content validity and reliability of the questionnaire were confirmed using the test-retest method $(r<0.8)$.

In this questionnaire, 10 items evaluated the epidemiological characteristics of the carrier couples, and seven items assessed the socioeconomic status of the family (i.e., education level, employment status, place of residence, possession of residential place, and type of medical insurance for both spouses). Each of the items was scored for the participants regarding their role in the status of family income, and total scores were calculated for both study groups.

Interviews with the participants were conducted by experienced female health workers. Scores below five were indicative of poor socioeconomic status, scores 5-10 were defined as moderate socioeconomic status, and scores 10-15 were interpreted as favorable socioeconomic status.

In this questionnaire, nine multiple-choice items and 11 true/false statements (total score: 20) were used to measure the knowledge of carrier couples about TDTM. As such, good knowledge was defined with total scores above $75 \%$, and acceptable knowledge was considered for total scores of $50-75 \%$.

In this study, attitude of the carrier couples was assessed via 16 items scored based on a threepoint Likert scale, as follows: totally agreed, partly agreed, partly disagreed, and totally disagreed. Positive, ambivalent and negative attitudes toward 
premarital screening and genetic counseling were considered for scores above, equal or lower than $33 \%$ of the total score, respectively.

Reproductive practice of TDTM carrier couples was evaluated in three items via interviews with the family members. Inappropriate reproductive practice was defined in the presence of one or some of the following circumstances: 1) fetal abortion without PND; 2) childbirth without PND and 3) having a child diagnosed with TDTM. Contraception methods used by the couples during the time of study were classified into two categories of safe (contraceptive pills, tubal ligation, vasectomy, menopause, and intrauterine device) and unsafe (withdrawal or abstinence methods).

Information of the participants remained confidential. Data analysis was performed in SPSS V.16 using descriptive statistics and Spearman's correlation-coefficient to determine the correlations between variables. In this study, $P$ value of less than 0.05 was considered significant.

\section{Results}

In total, 327 couples who were carriers of thalassemia minor were enrolled in this study. Among these subjects, 88 (26.9\%), 199 (60.8\%) and 40 families $(12.2 \%)$ were from the eastern, central and western parts of Mazandaran province,

Table 1. Demographic characteristics of carrier couples and control families (2012)

\begin{tabular}{lccc}
\hline $\begin{array}{l}\text { Epidemiological } \\
\text { Parameter }\end{array}$ & $\begin{array}{c}\text { Control Families } \\
(\mathbf{n}=\mathbf{6 6 0})\end{array}$ & $\begin{array}{c}\text { Carrier Couples } \\
(\mathbf{n}=\mathbf{3 2 7})\end{array}$ & P-value \\
\hline $\begin{array}{l}\text { Age of Women } \\
\text { Mean } \pm \text { SD) }\end{array}$ & $\begin{array}{c}35.5 \pm 10.7 \\
(95 \% \text { CI: } 14.1-56.9)\end{array}$ & $\begin{array}{c}27.2 \pm 6.9 \\
(95 \% \text { CI: } 13.4-41)\end{array}$ & 0.00 \\
\hline $\begin{array}{l}\text { Age of Men } \\
\text { Mean } \pm \text { SD) }\end{array}$ & $39.7 \pm 10.5$ & $31.7 \pm 7.7$ & 0.00 \\
\hline $\begin{array}{l}\text { Duration of } \\
\text { Marriage } \\
\text { (Mean } \pm \text { SD) }\end{array}$ & $14.6 \pm 10.6$ & $5.8 \pm 6.3 *$ & 0.000 \\
\hline $\begin{array}{l}\text { Total Years of } \\
\text { Marriage }\end{array}$ & 9618 & 1855 & 0.00 \\
\hline $\begin{array}{l}\text { Number of } \\
\text { Pregnancies }\end{array}$ & 1408 & $360 * *$ & 0.00 \\
\hline $\begin{array}{l}\text { Number of } \\
\text { Pregnancies per }\end{array}$ & $2.1 \pm 0.0$ & $1.1 \pm 0.0$ & 0.00 \\
$\begin{array}{l}\text { Family } \\
\text { Mean } \pm \text { SD) }\end{array}$ & & & \\
\hline $\begin{array}{l}\text { Favorable } \\
\text { Socioeconomic } \\
\text { Status }\end{array}$ & $201(30.5 \%)$ & $102(31.2 \%)$ & 0.1 \\
\hline
\end{tabular}

*Mann-Whitney U test; **One sample T-test
Table 2. Evaluation of negative attitudes of carrier couples toward screening, genetic counseling and *PND for prevention of thalassemia major (2012)

\begin{tabular}{llc}
\hline & Statements & Score \\
\hline $\mathbf{1}$ & I do not mind having a thalassemic child. & $\mathbf{1 2 2 5}$ \\
\hline $\mathbf{2}$ & I refuse to receive PND due to religious beliefs. & $\mathbf{1 1 9 3}$ \\
\hline $\mathbf{3}$ & Genetic counseling before marriage is not necessary. & $\mathbf{1 1 6 6}$ \\
\hline $\mathbf{4}$ & I wish I was not aware of being a minor. & $\mathbf{1 1 5 2}$ \\
\hline $\mathbf{5}$ & I think I am not accepted by the relatives of my spouse because & $\mathbf{1 1 5 0}$ \\
\hline $\mathbf{6}$ & I am a minor. & $\mathbf{1 1 3 8}$ \\
\hline $\mathbf{7}$ & I think my spouse regrets marrying me. & $\mathbf{1 1 3 6}$ \\
\hline $\mathbf{8}$ & If I am fortunate, I will have a healthy child without PND. & $\mathbf{1 0 9 9}$ \\
\hline
\end{tabular}

*PND: Prenatal Diagnosis

respectively. In addition, 660 control families were selected for the study, 174 (26.4\%), 406 (61.5\%), and $80(12.1 \%)$ of which were from the eastern, central, and western regions of the province. Demographic characteristics of the study groups are shown in Table 1.

First cousin marriage was reported in 103 (31.5\%) and $152(23 \%)$ carrier couples and control subjects, respectively. Level of knowledge was acceptable in $155(65 \%)$ and $456(74 \%)$ carrier couples and control subjects, respectively $(\mathrm{P}<0.006)$.

Moreover, the attitude toward genetic counseling was positive in $192(58 \%)$ and $254(41 \%)$ of TDTM carrier couples and control subjects, respectively $(\mathrm{P}<0.00)$.

Questionnaire items with the highest rate of negative and positive implications are shown in tables 2 and 3 .

In the case group, a significant correlation was observed between the level of knowledge and attitude regarding the reproductive behaviors

Table 3. Evaluation of positive attitudes of carrier couples toward screening, genetic counseling and PND for *TDTM (2012)

\begin{tabular}{llc}
\hline & Statements & Score \\
\hline $\mathbf{1}$ & $\begin{array}{l}\text { I believe that people should be aware of whether they are carriers } \\
\text { of thalassemia. }\end{array}$ & 1008 \\
\hline $\mathbf{2}$ & I will use PND if I am expecting a child. & 987 \\
\hline $\mathbf{3}$ & $\begin{array}{l}\text { Before marriage, I hoped to have many children, but since I am a } \\
\text { carrier, one or two children would be enough. }\end{array}$ & 950 \\
\hline $\mathbf{4}$ & I do not regret marrying another carrier. & 895 \\
\hline $\mathbf{5}$ & I would rather have an abortion than a sick child. & 895 \\
\hline $\mathbf{6}$ & I wish I had not married another carrier. & 790 \\
\hline *TDTM: Transfusion-dependent Thalassemia Major &
\end{tabular}

*TDTM: Transfusion-dependent Thalassemia Major 
Table 4. Reproductive practices of carrier couples and control families (2012)

\begin{tabular}{lccc}
\hline & $\begin{array}{c}\text { Control Families } \\
\text { N (\%) }\end{array}$ & $\begin{array}{c}\text { Carrier Couples } \\
\text { N (\%) }\end{array}$ & P \\
\hline PND & $8(1.2)$ & $114(34.9)$ & 0.00 \\
\hline Medical Abortion & $6(0.9)$ & $41(12.5)$ & 0.00 \\
\hline Reliable Contraception & $453(82.7)$ & $246(88.8)$ & 0.01 \\
\hline Illegal Abortion & $1(0.2)$ & $5(1.5)$ & 0.1 \\
\hline Thalassemic Child & 0 & $19(4.3 \%)$ & 0.003 \\
\hline $\begin{array}{l}\text { Pregnancy without } \\
\text { PND }\end{array}$ & $652(94.6)$ & $109(33.3 \%)$ & 0.000 \\
\hline
\end{tabular}

$(\mathrm{r}=0.001, \quad \mathrm{P}<0.00)$. However, no statistically significant correlation was observed between the knowledge and socioeconomic status of the participants $(\mathrm{P}=0.6)$. On the other hand, significant associations were observed between the place of residence (urban/rural) and socioeconomic status $(\mathrm{P}<0.000)$, and residence in urban areas and socioeconomic status of the case $(\mathrm{P}=0.02)$ and control subjects $(\mathrm{P}<0.001)$.

According to our findings, there were no significant relationships between place of residence, knowledge $(\mathrm{P}=0.8, \mathrm{P}=0.4)$, and attitude of the subjects $(\mathrm{P}=0.7, \mathrm{P}=0.6)$. Moreover, no significant links were observed between the age of the participants and their knowledge, attitude, and socioeconomic status.

Data on the use of PND by TDTM carrier couples are shown in Table 4. Among these couples, unfavorable practice since marriage regarding the use of PND was reported in 133 cases (Table 4). In other words, there were 14 cases of unfavorable practice by each couple per year, which resulted in the birth of 19 children affected by TDTM. In the case group, there were 98 children affected by TDTM per year for each couple (95\% CI: 97.498.6). In addition, 105 (32\%) and $286(43.3 \%)$ carrier couples and control families received family planning counseling in different healthcare centers, respectively.

With respect to family planning methods, $246(75.2 \%)$ and $453(68.5 \%)$ case and control subjects in this study used contraception methods, respectively. Other methods of family planning used by the participants are shown in Table 5 and Diagram 1.
Table 5. Use of contraception method in carrier couples and control families (2012)

\begin{tabular}{|c|c|c|c|}
\hline Status & $\begin{array}{c}\text { Control Families } \\
\text { N (\%) }\end{array}$ & $\begin{array}{c}\text { Carrier Couples } \\
\text { N (\%) }\end{array}$ & P-value \\
\hline Pregnant & $33(5.4 \%)$ & $26(8.8 \%)$ & 0.06 \\
\hline $\begin{array}{l}\text { Prevention of } \\
\text { Pregnancy }\end{array}$ & $469(76.37 \%)$ & $233(78.5 \%)$ & 0.9 \\
\hline Menopause & $62(10.1 \%)$ & $4(1.3 \%)$ & 0.000 \\
\hline Divorce & $3(0.5 \%)$ & $1(0.3 \%)$ & 0.5 \\
\hline Widowed & $10(1.6 \%)$ & 0 & 0.01 \\
\hline $\begin{array}{l}\text { Plan for Future } \\
\text { Pregnancy }\end{array}$ & $38(6.2 \%)$ & $3(11.1 \%)$ & 0.01 \\
\hline $\begin{array}{l}\text { Oral } \\
\text { Contraception }\end{array}$ & $133(20.2 \%)$ & $80(37.5 \%)$ & 0.1 \\
\hline *IUD & $16(2.7 \%)$ & $2(1.4 \%)$ & 0.04 \\
\hline Injection & $15(2.7 \%)$ & $4(0.4 \%)$ & 0.2 \\
\hline Condoms & $116(21.2 \%)$ & $107(39.7 \%)$ & 0.000 \\
\hline$* * \mathbf{T L}$ & $72(11.3 \%)$ & $7(2.1 \%)$ & 0.00 \\
\hline Vasectomy & $10(2 \%)$ & 0 & 0.01 \\
\hline $\begin{array}{l}\text { Natural } \\
\text { Methods } \\
\text { (unsafe) }\end{array}$ & $181(27.4 \%)$ & $61(16.2 \%)$ & 0.003 \\
\hline $\begin{array}{l}\text { Simultaneous } \\
\text { Use of Two } \\
\text { Contraception } \\
\text { Methods }\end{array}$ & $11(2 \%)$ & $6(2.3 \%)$ & 0.3 \\
\hline
\end{tabular}

*IUD: Intrauterine Device, **TL: Tubal Ligation

\section{Discussion}

According to the results of the present study, two-third of TDTM carrier couples had acceptable knowledge and more than half of these couples had positive attitudes toward premarital screening and genetic counseling, which confirms the efficacy of family planning programs in Iran.

Proper education regarding the etiology and prevention of thalassemia has been the cornerstone of the national family planning program during the past two decades (6). In the literature, several studies have evaluated the target populations for thalassemia confirming carrier couples as the most susceptible groups (8-11). For instance, a recent investigation was conducted on 764 thalassemic patients and carrier couples in the southern regions of Iran. According to the findings, approximately $26 \%$ and $74 \%$ of these individuals had poor or insufficient knowledge about PND (12).

In one study, Hemati et al. reported that $61.4 \%$, $30 \%$ and $8.6 \%$ of TDTM carrier couples had one, 


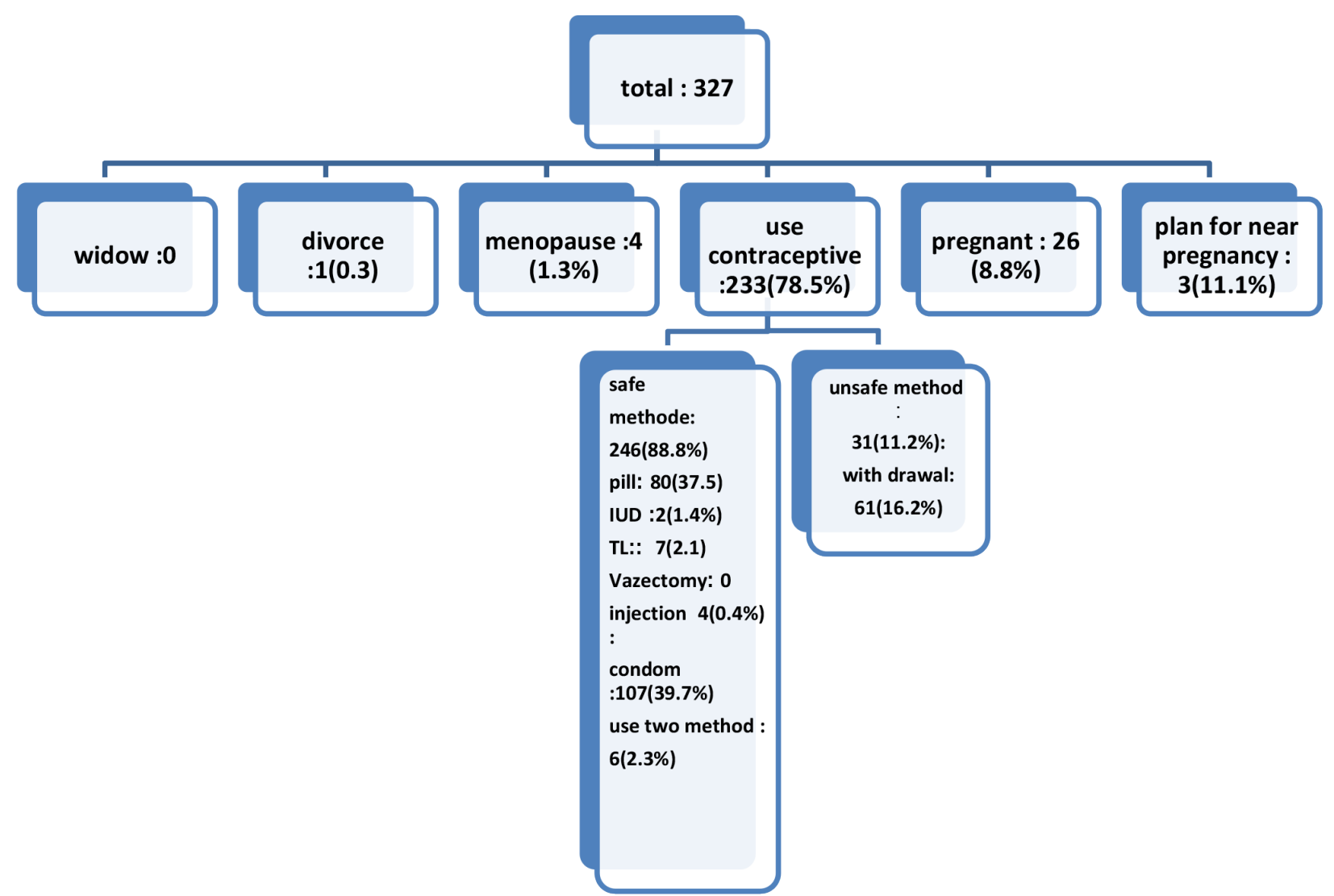

Diagram 1. Use of contraception methods in carrier couples (2012)

two, and three thalassemic children. Moreover, 67\% of the studied subjects had no knowledge of PND, while $70 \%$ had no information about the appropriate time of PND. This was mainly due to the lack of adequate information of the carrier couples about PND and other methods available for the prevention of thalassemia. In addition, $98 \%$ of these couples were against medical abortion (13).

In Mazandaran province, financial problems are known as the main obstacle against the use of the aforementioned methods; it is noteworthy that since the insurance coverage of PND and other prevention methods for TDTM in 2008, there has been a dramatic increase in the rate of PND (14).

In another study, Armeli et al. compared the knowledge of Italian, Italian- American, and nonItalian-American individuals about $\beta$-thalassemia, and acceptable knowledge was reported in 55\%, $17 \%$, and $24 \%$ of the subjects, respectively (15). In a similar study performed in the north of Iran, the majority of carrier couples had adequate knowledge $(82 \%)$ and positive attitudes (68\%) toward premarital screening for TDTM (3).

Another research was conducted in the southern regions of Iran to examine the attitude of 323 physicians toward the termination of pregnancy for the prevention of thalassemia major. According to the results, $91 \%$ of the physicians were in favor of this approach, and disagreements were mainly due to religious beliefs, emotional views, concerns about quality of care, and hopes to find new treatment options in the future (16). Since 2002, medical abortion before week 16 of gestation has been deemed legal in Iran (14). However, the final decision lies upon the parents and strongly depends on their religious and cultural inclinations (17).

In the present study, 114 (48\%) carrier couples did not use PND services. In our previous study conducted in 2009, pregnancy termination without 
PND was reported in $68 \%$ of the studied carrier couples (6), which was considered as a general progress.

According to the study by Gamberini et al. conducted in 1991 in Italy, 50\% of the pregnancies were terminated without PND in order to prevent thalassemia in the newborns. Among 77 couples, the main causes for pregnancy termination without PND were reported to be the presence of a normal child with a thalassemic child in the family (55.8\%), difficulties in the care of the thalassemic child (20.8\%), advanced age of the couple $(11.7 \%)$, fear of misdiagnosis $(7.8 \%)$, and refusal of abortion $(3.9 \%)(18)$.

In this regard, a cohort study was performed on nine carrier couples with 14 pregnancies, and all the subjects were reported to use PND (19). In the control group, length of marriage was five times more than the case group, while number of pregnancies was twice lower. This might be due to the younger age range of the couples in the case group. In another study, Habibzadeh evaluated 156 pregnancies in families with thalassemic children. According to the results, mean of normal and thalassemic children per family was 4.3 and 1.4 , respectively, and only $4.5 \%$ of the mothers had received genetic counseling before marriage. Among these mothers, mean of total number of children was significantly lower compared to other subjects (20). In the study by Hemati et al., mean of the total number of children per family was 3.7 (13), while in the study by Gamberini et al., this value was estimated at 1.8 and 1.6 in carrier couples and control subjects, respectively (18).

In the current study, regret for marrying another carrier was not a predominant emotion in the case group, while the most sensitive issue for these families was to have healthy children. However, some of these families relied on sheer chance for having a healthy child, which was probably a significant barrier against the use of PND.

In the present study, $30 \%$ of the children in the case group were reported to be thalassemic, and mean of unfavorable reproductive practices was estimated at 14 episodes per each family. Moreover, pregnancy termination $(\mathrm{n}=19)$ with thalassemia major was reported to be 14 cases per year in each family. Moreover, $90 \%$ of the carrier couples used reliable contraceptive methods.

In one research, Vicki compared the reproductive behavior between carrier and control couples and reported no differences in the sexual activity, use of contraception, number of children, and employment status of these groups (2).

One of the interesting findings of the current study was that families who were not at risk of genetic diseases used PND and medical abortion in eight and six cases, respectively. This could be due to the increased use of routine ultrasound scans during pregnancy and possibility of medical abortions for major fetal abnormalities, incompatibility with life, and problematic intellectual development of the fetus. With regard to religious beliefs on medical abortion, the legal ground dictates that termination of pregnancy depends on parental choice to endure "Osr and Haraj", which means "great suffering", in raising the child (21-29). One of the limitations in the current study was that we were not able to evaluate the rate of illegal abortions due to the sensitivity of this issue.

In conclusion, the results of this study indicated that knowledge of carrier couples regarding TDTM was relatively adequate, and they commonly had positive attitudes toward PND. However, reproductive behavior of these couples needed to be improved through different strategies. Therefore, it is recommended that TDTM carrier couples be monitored regularly in order to diminish unfavorable reproductive behaviors and reinforce the implementation of family planning programs.

\section{Conflicts of interest}

None declared.

\section{Authors' contributions}

MR Mirzayi and M Zafari performed the statistical analysis. M Zafari collected the data. M Kosariyan contributed to manuscript writing and drafting. 


\section{Acknowledgments}

Hereby, we extend our gratitude to Professor Enayati, the Vice Chancellor of Research at Mazandaran University of Medical Sciences. We would also like to thank Ms Zakizadeh (controlling of non-communicable diseases) and all the couples who assisted us in this research project. This study was financially supported by Mazandaran University of Medical Sciences.

\section{References}

1. Sheiner E, Levy A, Yerushalmi R, Katz M. Betathalassemia minor during pregnancy. Obstet Gyneacol 2004; 103(6):1273-7.

2. Psihogios V, Rodda C, Reid E, Clark M, Clark C, Bowden D. Reproductive health in individual with homozygouse beta-thalassemia: knowledge, attitude, and behaviour. Fertil Steril 2002; 77(1):119-27.

3. Kosarian M, Vahidshahi K, Siami R, Nazari M, Karami $\mathrm{H}$, Ehteshami S. Knowlege, attitude, and practice of reproductive behaviour in Iranian minor thalassemia couples. Saudi Med J 2009; 30(6):835-9.

4. Toumba M, Kanaris C, Simamonian K, Skordis N. Outcome and management of pregnancy in women with thalassemia in cyprus. East Mediterr Health J 2008; 14(3):628-35.

5. Samavat A, Modell B. Iranian national thalassemia screening programme. BMJ 2004; 329(7475):1134-7.

6. Khorasani G, Kosaryan M, Vahidshahi K, Shakeri S, Nasehi MM. Result of the national program for prevention of betathalassemia major in the Iranian province of Mazandaran. Hemoglobin 2008; 32(3):263-71.

7. Abolghasemi H, Amid A, Zeinali S, Radfar M, Eshghi P, Rahiminejad MS, et al. Thalassemia in Iran: epidemiology, prevention, and management. J Pediatr Hematol Oncol 2007; 29(4):233-8.

8. Amooee S, Samsami A, Jahanbakhsh J, Karimi M. The pregnancy outcome in patients with minor $\beta$-thalassemia. Iran J Reprod Med 2011; 9(1):9-14.

9. Fairweather D, Modell B, Berdoukas V, Alter BP, Nathan DG, Loukopoulos D, et al. Antenatal diagnosis of thalasemia major. Br Med J 1978; 1(6106):350-3.

10. Pan HF, Long GF, Li Q, Feng YN, Lei ZY, Wei HW, et al. Current status of thalassemia in minority populations in Guangxi, China. Clin Genet 2007; 71(5):419-26.

11. Rahmanpour H, Honarbakhsh M. Prevalence of thalassemia minor for prevention of thalassemia in Tarom. J Zanjan Univ Med Sci 1999; 22(6):21-7 (Persian).

12. Karami H, Kosaryan M, Abolghasemi H, Rashidighader F, Vahidshahi K, Dabirian M. Deferiprone plus deferoxamine versus deferoxamine iron chalation in beta thalassemia major. Sci J Iran Blood Trans Organ 2010; 7(4):227-34.

13. Hemati M. Knolege of parents with thalasemia major about PND during pregnancy and abortion therapy. 8th seminar fertility \& infertility. Kermanshah, Iran: Kermanshah University of Medical Science; 2003.

14. Abolghasemi H, Amid A, Zeinali S, Radfar MH, Eshghi P, Rahiminejad MS, et al. Thalassemia in Iran: epidemiology, prevention, and management. J Pedier Hematol Oncol 2007; 29(4):233-8.

15. Armeli C, Robbins SJ, Eunpu D. Comparing knowlege of beta-thalassemia in samples of Italian, Italian-American, non-Italian-Americans. J Genet Couns 2005; 14(5):365-76.

16. Karimi M, Bonyadi M, Ghalehdari M, Zareifar S. Termination of pregnancy due to thalassemia major, hemophilia, and Down's syndrom: the views of Iranian physicians. BMC Med Ethics 2008; 9:19-23.

17. Rahmaninejad MS, Zeinali S, Afrasiabi A, Valeshabad AK. $\beta$-thalassemia mutations found during 1 year of prenatal diagnoses in Fars province, Iran. Hemoglobin 2011; 35(4):331-7.

18. Gamberini MR, Lucci M, Vullo C, Anderson B, Canella R, Barrai I. Reproductive behaviour of families segregation for cooley's anaemia befor and after the availability of prenatal diagnosis. J Med Genet 1991; 28(8):523-9.

19. Mitchell JJ, Capue A, Clow C, Scriver CR. Twenty-year outcome analysis of genetic screening program for Taysachs and beta-thalassemia disease carriers in high school. Am J Hum Genet 1996; 59(4):793-8.

20. Habibzadeh F, Yadollahie M, Roshanipoor M, Haghshenas M. Reproductive behaviour of mothers of children with beta-thalassaemia major. East Mediterr Health J 2012; 18(3):246-9.

21. Khamenei SA. Fatwas. The Office of the Supreme Leader. Available at: URL: http://www.leader.ir/; 2011.

22. Saanei YGA. Fatwas. Grand Ayatullah Saanei. Available at: URL: http://www.saanei.org; 2007.

23. Sistani SAH. The Official Website of the Office of His Eminence. Available at: URL: http://www.sistani.org; 2007.

24. Makarem- Shirazi NGA. Fatwa. The Official Website of Grand Ayatollah Makarem Shirazi. Available at: URL: http://www.makarem.ir; 2007. 
25. Fazel Lankarani M. The Official Website of Grand Ayatollah Muhammad Fazel Lankarani. Available at: URL: http://www.lankarani.org/; 2011.

26. Ministry of health of Islamic republic of Iran Deputy of Health. Scientific documents regarding abortion (the proposed guideline); 2005.

27. Larijani B, Zahedi F. Changing parameters for abortion in
Iran. Indian J Med Ethic 2006; 3(4):131-1.

28. Asnafi N, Akhavan-Niaki H. Pregnancy outcome of chorionic villus sampling on 260 couples with betathalassemia trait in north of iran. Acta Med Iran 2010; 48(3):168-71.

29. Albar MA. Counselling about genetic disease: an Islamic perspective. East Mediterr Health J 1999; 5(6):1129-33. 